\title{
IRON TOXICITY, TOLERANCE AND QUANTITATIVE TRAIT LOCI MAPPING IN RICE; A REVIEW
}

\author{
RAsheEd, A. ${ }^{1}$ - HASSAN, M. U. ${ }^{2}-$ AAMER, M. ${ }^{2}-$ BiAn, J. M. ${ }^{1}-$ XU, Z. R. ${ }^{1}-$ HE, X. F. ${ }^{1}-$ \\ YAN, G. ${ }^{1}-$ WU, Z. M. ${ }^{1 *}$ \\ ${ }^{1}$ Key Laboratory of Crop Physiology, Ecology and Genetic Breeding, Ministry of \\ Education/Collage of Agronomy, Jiangxi Agricultural University, Nanchang 330045, P.R.
} China

${ }^{2}$ Research Centre on Ecological Sciences, Jiangxi Agricultural University, Nanchang 330045, P.R. China

*Corresponding author

e-mail:wuzmjxau@163.com,phone: +86-791-8382-8113

(Received 14 $4^{\text {th }}$ Feb 2020; accepted 29 ${ }^{\text {th }}$ Jul 2020)

\begin{abstract}
Rice being a big staple food, faces many abiotic stresses, resulting in a yield reduction. Iron $(\mathrm{Fe})$ has many key roles for plants in sustaining growth and production, however, Fe toxicity is a big threat to rice production worldwide. There are many regulation mechanisms in rice to ensure an adequate supply of Fe to plant and to prevent deleterious effects. Rice is adopted many physiological and molecular mechanisms to cope with Fe toxicity in flooded soils, however, rice tolerance to Fe toxicity varies greatly and this mechanism has not fully understood. Efforts are being made to unfold the genetic basis of Fe toxicity tolerance in rice. There are many regulators discussed here, which are responsible for Fe uptake and transport from rhizosphere to the plants. Toxic effects of $\mathrm{Fe}$ on rice, the genes advocating the regulation of $\mathrm{Fe}$, and many quantitative traits loci governing $\mathrm{Fe}$ toxicity tolerance in rice are discussed here. Many putative QTL involved in rice tolerance to Fe toxicity are presented in this review. The identification of QTL and regulators for Fe toxicity tolerance would be more helpful in regulating $\mathrm{Fe}$ toxicity and developing Fe tolerant lines in rice. More efficient breeding techniques are required to screen Fe tolerant rice genotypes. This review focused on some possible ways to improve Fe toxicity tolerance in rice and provide a strong theoretical base for future research.
\end{abstract}

Keywords: iron; toxicity, genes, $Q T L$, regulation, rice, mapping population

Abbreviations: AB: Abscisic Acid, NSP: Number of spikelet's/plant, BIL: Backcross inbred lines, OA: Organic Acid, BRILs: Backcross recombinant inbred lines, QTL: Quantitative trait loci, CC: Chlorophyll content, RIL: Recombinant inbred lines, Chr: Chromosomes, RL: Root length $(\mathrm{cm}), \mathrm{Cm}$ : Centimeter, ROS: Reactive oxygen species, CSSL: Chromosomal segment substitution liens, DH: Double haploid, RDW: Root dry weight (mg), Fe: Iron, SWC: Shoot water content, GW: Grain weight, SL: Shoot length (cm), IL: Introgression line, LBI: Leaf bronzing index, MG: Magic population.

\section{Introduction}

Rice is the main cereal and staple crop for almost $50 \%$ of the world's population (Mahender et al., 2019; Rasheed et al., 2020a). Rice yield is expected to increase by 100 tons to feed the 9.1 billion population of the world by 2050 (Jaggard et al., 2010). Rice crop is facing many abiotic and biotic stresses including drought, heat, salinity, cold and nutrient deficiencies and most importantly the Fe toxicity (Mahender et al., 2019; Rasheed et al., 2020b). Fe toxicity is one of the leading restrictions for rice growth in many soil and a lot of studies have been conducted on understanding the genetic base of this stress (Bashir et al., 2014; Mahender et al., 2019). 
Fe has many significant functions in rice-like, photosynthesis, homeostasis, and mitochondrial respiration (Nakanishi et al., 2006; Kim and Guerinot, 2007; Li et al., 2017). About $18 \%$ of soils globally are suffering from Fe toxicity and Fe deficiency (Saikia and Baruah, 2012; Das and Roychoudhury, 2014; Dufey et al., 2015), which results in a change in soil $\mathrm{pH}$, soil fertility status and many other alterations in soil properties (Audebert and Sahrawat, 2000; Audebert, 2006). In many crops 50\% reduction in grain yield has been reported owing to Fe toxicity, however, complete crop failure has also been observed during the early growth stage. Fe toxicity usually affects rice shoot length (SL), root length (RL) and also results in leaf bronzing which is a primary symptom of Fe toxicity in rice (Dufey et al., 2009).

Fe toxicity often occurs in alkaline soils, which leads to rise in $\mathrm{pH}$, an increase in the amount of calcium carbonate and nitrate, a change in temperature and poor aeration (Kobayashi et al., 2014; Mongon et al., 2017). Several factors such as poor drainage, soil organic matter content, more hydrogen sulfides, low soil fertility and genotypes lead to an increase in available forms of Fe in soil (Chandel et al., 2010; Mahender et al., 2019). Rice plants adopted several mechanisms to cope with Fe toxicity in soil, like reducing Fe uptake and chelation through chelating agents, trafficking and storing in less responsive type, but most important is the expression of resistance genes (Dufey et al., 2009; Zhang et al., 2017).

QTL mapping is one of the powerful approaches to identify the genes of interest on the chromosome. In order to locate the gene of interest on chromosome, we need to screen genotypes of rice against Fe toxicity. A lot of QTL have been reported in rice for Fe toxicity tolerance using several mapping populations (Jain and Connolly, 2013; Zhang et al., 2017; Meng et al., 2017). Breeding Fe resistant varieties is an economically important approach to enhance rice production under Fe toxicity stress and Fe toxicity is controlled by many genes in rice (Dufey et al., 2012; Wainaina et al., 2018). A lot of genes have been reported in rice which is responsible for rice tolerance to Fe toxicity and these genes belong to five major protein families (OsFROs and OsFERS) (Chandel et al., 2010). Most of QTL reported in rice against Fe toxicity tolerance belongs to easily measurable traits, like seedling length, root length, seedling fresh and dry weight (Zhao et al., 2013; Dufey et al., 2015; Liu et al., 2016; Meng et al., 2017). The understanding of the Fe tolerance mechanism in rice is important to develop rice varieties tolerant to $\mathrm{Fe}$ toxicity. In this review we discussed the recent advancements on rice tolerance to Fe toxicity and ways to improve rice production in $\mathrm{Fe}$ affected soils and moreover, a view on identified QTL for Fe toxicity tolerance in rice is also discussed here.

\section{Role of $\mathrm{Fe}$ in plants and rice}

Fe has many roles in plants such as nutrients transport, mitochondrial respiration, photosynthesis, regulation of several enzymes and nitrogen assimilation (Bashir et al., 2010; Wu et al., 2014; Brumbarova et al., 2015). The regulation of protein stability is also performed by $\mathrm{Fe}$ and it also takes part in many chemical reactions such as, hydration, dehydration, redox-dependent catalysis, photo redox catalysis which detoxify excessive $\mathrm{Fe}$, thus, $\mathrm{Fe}$ is one of the essential mineral element for plants (Zhang et al., 2013; Jain and Connolly, 2013; Dufey et al., 2015). Fe accelerates many antioxidant defense mechanisms such as, superoxide dismutase, catalase, polyphenol oxidase which protects rice plants from oxidative damage, which helps to screen Fe tolerant rice 
cultivars (Saikia and Baruah, 2012; Pennock et al., 2015). The photosynthesis process is facilitated by $\mathrm{Fe}$; owing to the fact $90 \%$ of $\mathrm{Fe}$ is present in plastids to maintain the structural integrity of the thylakoid membrane (Rout and Sahoo, 2015; Mahender et al., 2019).

\section{Iron toxicity in rice}

In the case of Fe toxicity, cell division occurs and leaves turned into white and results in stunted growth (Vejchasarn et al., 2016; Banakrt et al., 2017). An excessive amount of $\mathrm{Fe}$ results in cellular oxidative damage and leads to several changes in morpho-physiological and yield traits of rice (Hell and Stephan, 2003; Sikirou et al., 2015). Iron toxicity lead to blockage of important nutrients essential for rice growth (Audebert and Sahrawat, 2000; Nughara et al., 2016) and complete crop failure can occur if Fe toxicity becomes more severe (Audebert, 2006; Li et al., 2016). A surplus quantity of $\mathrm{Fe}$ is firstly responsible for Fenton reaction and it produces hydroxyl radicals $(-\mathrm{OH})$ and reactive oxygen species (ROS), induce permanent injury to the membrane lipid, protein and genetic material. The ROS resulting in oxidized chlorophyll and successively decrease the photosynthesis, and leads to chlorosis (a major yield-reducing factor) (Mengel, 1995; Onaga et al., 2016).

\section{How Fe toxicity arises is soil}

$\mathrm{Fe}$ in soil under anaerobic condition converted from $\mathrm{Fe}^{3+}$ to $\mathrm{Fe}^{2+}$ due to low $\mathrm{pH}$ and becomes toxic for plants. Fe prevalently occurs in the soluble and reduced ferrous form $\left(\mathrm{Fe}^{2+}\right)$ due to low soil redox potential arising from anaerobic conditions, which are developed when soil microorganisms and plant roots deplete oxygen by respiration. The excessive $\mathrm{Fe}$ molecules are transported via xylem flow to the shoot leading to $\mathrm{Fe}$ toxicity which is one of the main nutrient disorder in rice (Frei et al., 2016; Van Ort, 2018).

\section{Iron uptake, transport and assimilation in rice grains}

Fe uptake, transport from root to shoot and grain are essential for normal plant growth. Fe can be transported in various forms through xylem and phloem including Fecitrate, DMA-Fe (III), and NA-Fe (II). OsFRDL1 is involved in Fe homeostasis in rice via xylem. There are 18 putative YSL family genes in rice, out of them OsYSL5-7, 14 and -17 are mainly expressed at epidermis, cortex and stele of the Fe sufficient and Fe deficient rice roots. The expression of OSYSL1-4, 9-11 and -18 was not studied in roots. OsYSL12 is expressed in cortex and stele in both Fe deficient and sufficient condition whereas, OsYSL12 is expressed in the cortex and stele under Fe sufficient OsYSL6 was expressed in the epidermis in under Fe-sufficient condition only (Inoue et al., 2008). Among these mutant genes, OsYSL2, OsYSL-15 and OsYSL18 have been studied in detail (Aoyama et al., 2009; Ishimaru et al., 2010). OsYSL15 transports $\mathrm{Fe}^{2+}$ DMA from the rhizosphere to the roots and is involved in internal Fe homeostasis. OsYSL15 promoter driven GUS expression was only observed in leaf tissue but also at the flowering stage (Inoue et al., 2009). These all studies indicated that OsYSL15 is involved in $\mathrm{Fe}$ transport and assimilation in rice grains. OSYSL2 is also involved in $\mathrm{Fe}$ assimilation in rice seeds (Koike et al., 2004). OsYSL15 and OsYSL12 contributed 
widely for $\mathrm{Fe}$ translocation during germination. Some of the studies suggested that OsYSL2 is important for Fe translocation in seeds (Nozoye et al., 2007). Fe distribution and localization in grains is shown in Figure 1.

$\mathbf{a}$
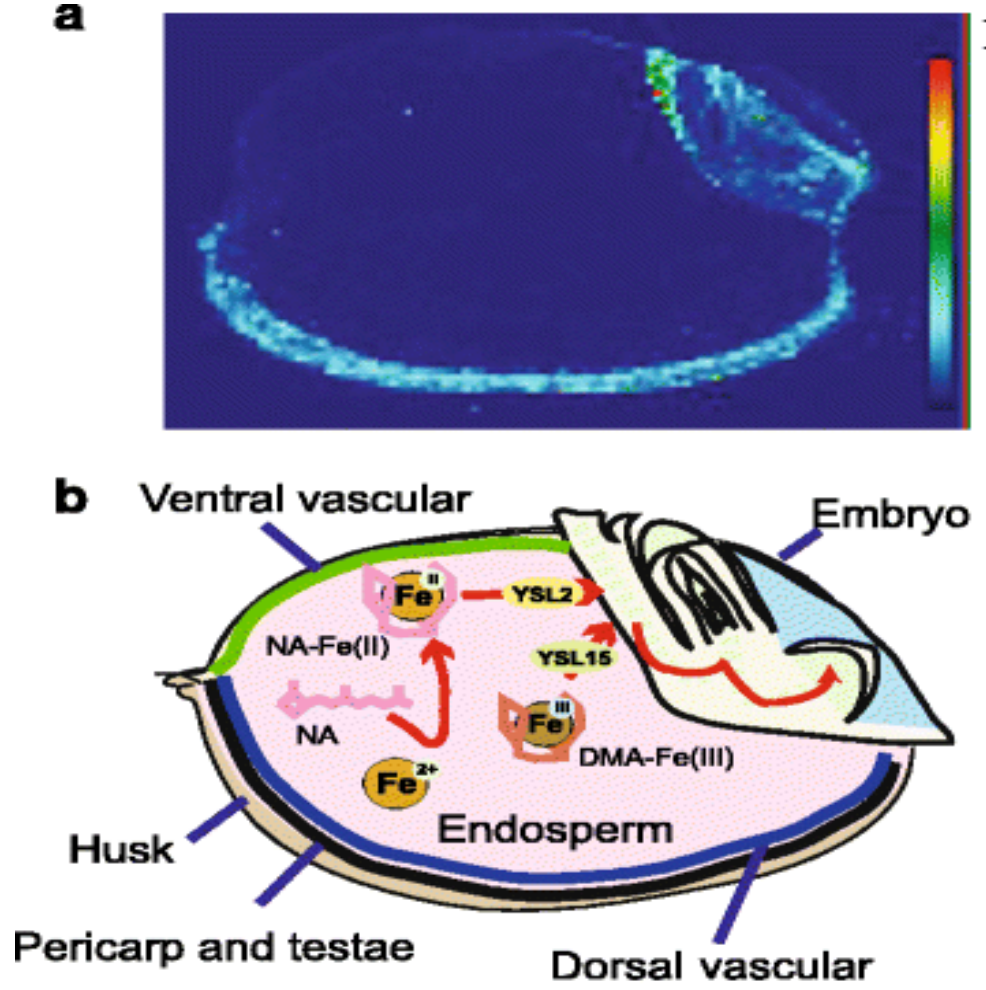

High

Low

\section{NA production area}

\section{DMA production area}

\section{NA and DMA production area}

Figure 1. Fe distribution, localization in seeds, and production of DMA, and NA, and iron distribution during germination. Taken from (Bashir et al., 2010)

\section{Iron toxicity tolerance mechanism in rice}

Some studies give a shred of evidence; rice can be grown under Fe toxicity conditions without any loss in yield (Onaga et al., 2013; Mahender et al., 2019). There are three possible mechanisms of rice tolerance to $\mathrm{Fe}$ toxicity are documented; exclusion of Fe from root, storage in plant parts and tissues (Wan et al., 2003; Müller et al., 2015). The genotypes adopted three types of procedures to exclude Fe from roots, oxidation of $\mathrm{Fe}$ from root which result in low concentration of Fe in nutrient solution, elimination of $\mathrm{Fe}$ at root surface, and most remarkable strategy adopted by rice genotypes is formation of aerenchyma and lateral roots which provided low resistant pathway for oxygen transport into rhizosphere where iron is oxidized into less toxic form (Wu et al., 2019; Mahender et al., 2019). Many studies evidenced the tissue tolerance mechanism for rice tolerance against Fe toxicity (Hosseni et al., 2012; Muller et al., 2015; Frei et al., 2016), which is regulated by nitrous oxide signaling pathway, signaling storage proteins and enzymes, reactive oxygen species (ROS) and hormones etc. ROS are neutralized by nitrous oxide by its function (Darbani et al., 2013; Onaga et 
al., 2016). Nitrous oxide also regulates, kinase protein, calcium, cycling GMP, cyclic ADP-Rib, via S-nitrosylation of Cys deposits (Besson-Bard et al., 2009). $\mathrm{N}_{2} \mathrm{O}$ also mediates Fe storage protein (ferritin) at both messenger RNA and protein level and an ARFAT an auxin-responsive element described which represented in 400 up-regulated genetic factors below Fe harmfulness (White and Brown, 2010). This mechanism is still unclear that either Fe regulates this auxin signaling protein or it is independent of $\mathrm{Fe}$ modulation and further studies are required on this aspect.

\section{Iron storage in sub-cellular compartments}

Once Fe is entered into the cell, there are certain steps inside the cell to stop Fe or mediate its toxicity. Many scavenging elements like nitrous oxide, DMA act as chelators of $\mathrm{Fe}$ and started scavenging of $\mathrm{Fe}$ at a sub-cellular level by forming a complex (Onaga et al., 2016). In rice the transporters of metals at inter and intracellular levels are categorized as in natural resistance-related protein (macrophage NRAMP) for cation carrier (Takahashi et al., 2011, Tan et al., 2019). OsNRAMP1 is up-regulated by deficiency of $\mathrm{Fe}$ and $O S N R A M P 7 \& 8$ showed a negative association with $\mathrm{Fe}$ concentration in shoots. OSNRAMP1 most likely work as metal efflux carrier contributing in the transfer of metals from the section of vacuole to cystol and, OsNRAMP7, OsNRAMP8 play role as metals influx protein which worked as sequestration of metals in the vacuole (Ogo et al., 2014). OsNRAMP6 is regulated with OsVIT1 in rice grown under surplus iron (Vivitha et al., 2017; Mahender et al., 2019). This showed that NRAMP6 is responsible for transfer of Fe from cell to vacuoles and chloroplast, thereby increasing Fe toxicity tolerance in rice. OsVIT2 is up-regulated in rice shoot and root in reaction to excessive Fe (Bashir et al., 2014), proposing that OsVITI \& OSVIT2 had a function in the compartmentalization of Fe (Wu et al., 2019). The transporter VIT1 has been studied to be functional by organizing with AtNRAMP3 and AtNRAMP4; the two isologs of Arabidopsis on the surface of the vacuolar membrane of roots and shoots under Fe deficiency (Onaga et al., 2016). OsVITI and OsVIT2 are more functional in rice when rice is grown under Fe toxicity stress. OsVIT1 and OsVIT2 are congested in rice under Fe shortage (Zhang et al., 2013). The unpredictable function of transporter (VIT1) in Arabidopsis and rice showed that VIT1 also interacts with other regulators carry $\mathrm{Fe}$ in the vacuole, and function as diverting the release of $\mathrm{Fe}$ into cells of vacuole in absence of Fe through modifying the action of AtNRAMP3 and AtNRAMP4 (Zhao et al., 2013; Onaga et al., 2016). The transport OsNRAMP5; is existing in the plasma membrane and it is involved in reducing $\mathrm{Fe}$ concentration in roots and shoots through xylem (Ishimaru et al., 2012). Many plants carrying OsNTAMP5i store less $\mathrm{Fe}$ in shoot and xylem sap, indicating that this transporter cooperates with different other Fe transporters to regulate iron in shoots of rice (Morrissey and Guerinot, 2009; Wu et al., 2019; Mahender et al., 2019).

\section{Chloroplast}

Fe toxicity is also regulated in the chloroplast, where FRO7 a member of FRO localized in plastids showed that Fe is reduced by AtFRO7 in rice and Arabidopsis and then taken by $\mathrm{Fe}^{2+}$ carrier. Inner membrane-localized permease is considered to be the main site for Fe distribution into chloroplast (Zhang et al., 2017). OsFRO1 is connected to AtFRO7, and may show the same role converting $\mathrm{Fe}^{3+}$ to $\mathrm{Fe}^{2+}$, in preparations for transport into the chloroplasts (Sperotto et al., 2010). The genes regulating ferritin have 
been recognized in various species of plants mainly in rice (Matthus et al., 2015). The up-regulation of genes in reaction to surplus Fe (Bashir et al., 2014; Onaga et al., 2016; Onyango et al., 2019) reveals that ferritin is effective paths of intracellular Fe in the rice (Onaga et al., 2016).

\section{Mitochondrial chelation of Fe}

The Fe can also be deposited in mitochondrial section where protein ferritin exists. (Lin et al., 2011) exhibited that over expression of a mitochondrial Fe carrier, mitochondrial RNA splicing (MRS3), in yeast over-whelms the expansion of Fe toxicity by declining cytosolic Fe via mitochondrial Fe increase. Orthologue of (MSR3) is a Fe carrier in mitochondria which was recognized as accountable for carrying $\mathrm{Fe}$ into mitochondria (Bashir et al., 2011; Mahender et al., 2019). The suppression of MIT lead to decrease in aconitase activity, specifying that mitochondrial $\mathrm{Fe}$ transporter is important for Fe s-cluster biogenesis in cytoplasm and mitochondria. Gross et al. (2003) and Bashir et al. (2014) have discovered the contradictory track for these genetic factors. The regulation of (OsNAS1, OsNAS2, OsNAAT1, and OsNRAMP1) was witnessed, possibly to avoid unnecessary uptake and toxicity of Fe. Five major protein families of Fe tolerance genes are OsNRAMPs, OsFROs, OsZIPs, OsFERs and OsYSLs. Fe toxicity and deficiency up and down regulated genes in rice are shown in Figure 2.

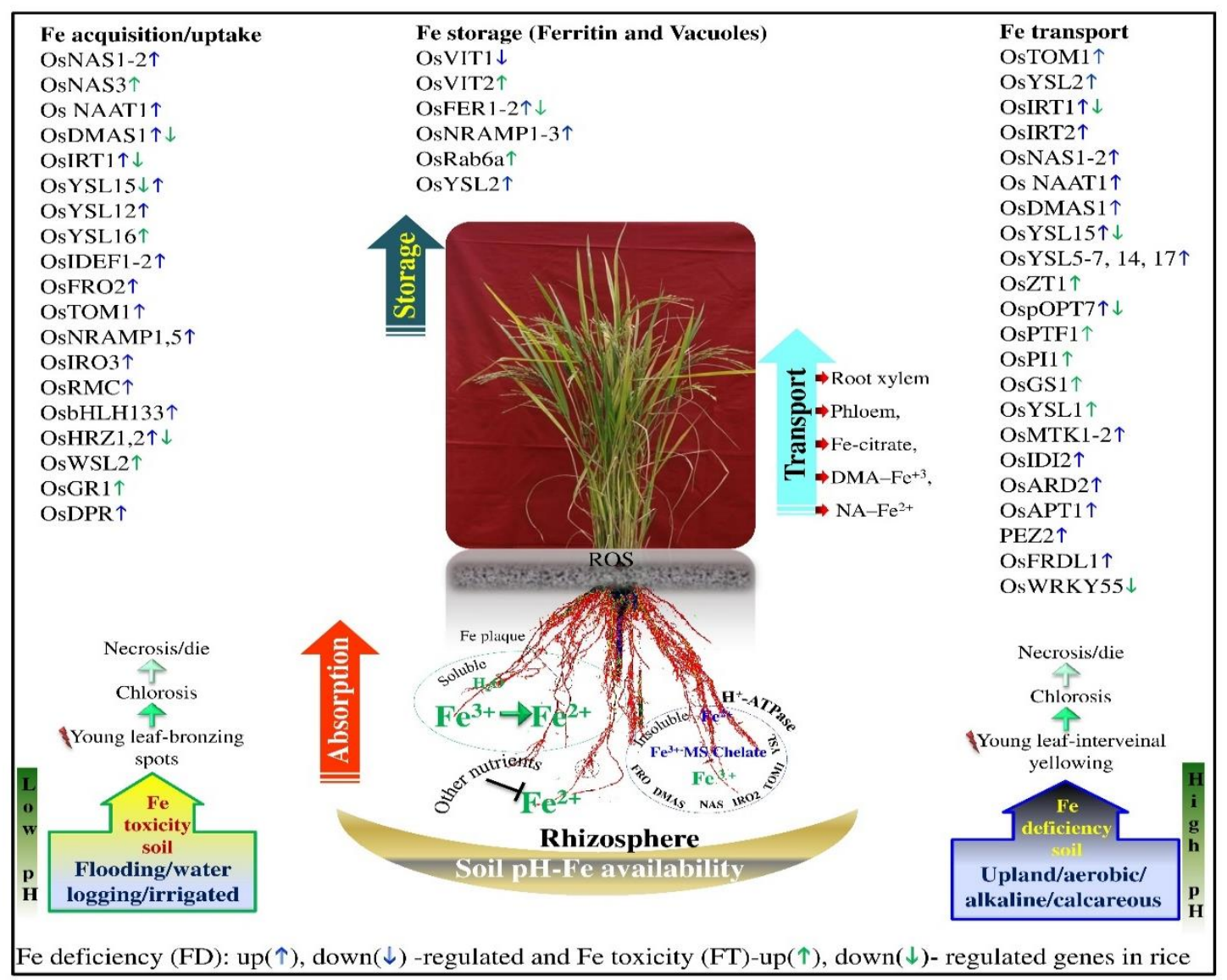

Figure 2. Fe toxicity and deficiency up and down regulated genes showing alterations in levels of transcription through microarray and transcriptomics studies (Adopted from Mahender et al., 2019) 


\section{Regulation of Fe uptake}

The regulation of Fe uptake is done by many TFs transcription factors and regulators including, signal transducers. Plants adopt strategy II in response to Fe deficiency, like enhance biosynthesis along with secretion of $\mathrm{Fe}^{3+}$ chelator named Mas (mugenic acid). Some enzymes, which are main target of transcription factors contributed to mugenic acids (Inoue et al., 2008). A gene (OsFRO2), cool with OsNAAT1 and OsVIT1 and protein $O s R M C$ work as receptor, involved in Fe regulation in rice (Finatto et al., 2015; Onaga et al., 2016; Wu et al., 2019). The transcription factors prompted by $\mathrm{Fe}$ deficiency, (OsIRO3 \& OsbHL133) were characterized in rice (Wang et al., 2012). Some other genes like (IDEFI \& OsHRZ1-2) were studied to catch Fe signals through binding of $\mathrm{Fe}$ and zinc and avoid surplus Fe uptake under sufficient Fe availability (Liu et al., 2016). Most meaningful is to conclude that there are some genes which can interact in vivo with $O s H R Z$ and to find that this post-transcriptional modification can be helpful to enhance Fe toxicity tolerance in rice (Onaga et al., 2016; Mahender et al., 2019). Post-transcriptional regulation of Fe in rice has not fully understood, therefore, it will be significant to unfold the natural variation for $O s R T 1$ with stable disparity deposit replacement in its loop that may enhance tolerance to Fe toxicity in rice. The studies on link between amid the residue replacements in OsIRTI with action of OsHRZ and IDEF 1 can add significant benefit in studying post-translational alteration of Fe uptake in rice (Onaga et al., 2016). The earlier studies described the role of ABA (abscisic acids) and brassinosterioids, in regulation of IDE1 modulation of downstream target in Fe homeostasis single transductions mechanisms need to be unfold (Gallie, 2012; Pereira et al., 2014). Rice has a number of strategies to switch unnecessary Fe uptake.

Fe storage genes which are encoding VOT, FPN2 transporter are well regulated and thus Fe may engage in old leaves. The similar genetic factors could be controlled in shoot of includer that positively stock Fe in plant aerial parts. Additionally, genes encoding YSL4 and YSL6 like Fe efflux carriers, could be controlled to release spare Fe from chloroplast, to stop oxidative damage. It would be valuable to detect important genes, with constant influence in reaction to the dissimilar kinds of Fe harmfulness, to use for breeding's schemes. The only one author reported the confirmed effects of Fe nutrition gene (OSFRO1) in tolerance of Fe toxicity (Mahender et al., 2019), despite lot of research work has been accomplished. Transporters identified regarding Fe regulated genes and their function are shown in Table 1.

Table 1. Transporters identified regarding Fe regulated genes and their function

\begin{tabular}{|c|c|c|c|}
\hline Genes & Position & Role & Reference \\
\hline OsZIP4 & Root & $\begin{array}{c}\text { Zinc transporting proteins, Fe transport and } \\
\text { homeostasis }\end{array}$ & (Quinet et al., 2012) \\
\hline OsYSL2 & Root & $\begin{array}{l}\text { Fe-NA transport, } \mathrm{Fe} \text { accumulation in seeds } \\
\text { and translocation in grains }\end{array}$ & (Koike et al., 2004) \\
\hline OSPIC1 & Chloroplast & Transport Fe from root to chloroplast & (Zhang et al., 2012) \\
\hline OsFRO2 & Root & Alter Fe oxidation state & (Stein et al., 2009) \\
\hline OsVIT1,2 & Leaves/Seeds & Vacuolar Fe transporter & (Zhang et al., 2012) \\
\hline OsMIR & Shoot & Fe homeostasis & (Ishimaru et al., 2010) \\
\hline OsFERI & $\begin{array}{l}\text { Aleurone } \\
\text { layer }\end{array}$ & Vacuolar Fe transport and homeostasis & (Bashir et al., 2013) \\
\hline
\end{tabular}




\section{QTL identified for rice tolerance to Fe toxicity}

The identification and isolation of QTL linked to Fe tolerance is a powerful way to improve the rice tolerance to Fe toxicity (Dramé et al., 2011; Mahender et al., 2019). A lot of mapping populations are used in many studies, which have identified many QTL in rice. Here we discussed some QTL identified previously and their role in iron toxicity tolerance. $\mathrm{Wu}$ et al. (2014) used a mapping population of RIL (recombinant inbred liens) derived from IR29/Pokkali and identified two putative QTL for leaf bronzing score $q F E T O X-1-1$ and $q F E T O X-1-2$ between the markers with $10.6 \%$ and $12 \%$ phenotypic variation. The LBI indicated the large genetic variation among the parental genotypes for tolerance to Fe toxicity. A variety of traits like, SL, RL, shoot dry weight (SDW) and root dry weight (RDW) are also used for estimation of Fe toxicity tolerance in rice. Two QTL for SL and RL were reported by Meng et al. (2017) using 873 RIL (recombinant inbred lines) derived from MAGIC populations. QTL $q S L-1$ and $q R L-8$ were identified with $18 \%$ phenotypic variation.

This trait indicated large genetic variability for Fe tolerance. Many genes were reported behind these QTL controlling Fe toxicity tolerance in rice. Dufey et al. (2010) used 164 RIL (recombinant inbred liens) population evaluated in multiple environment, and identified one putative QTL $q N S P$-3 for number of spikelet's in rice which showed large variation for iron toxicity tolerance. Likewise, Dufey et al. (2012) identified two more QTL using same population for 1000 grain $q G W-1$ weight and chlorophyll content $q C C 1-7$ with varying ratio of variance. Dufey et al. (2015) conducted a hydroponic experiment and evaluated $220 \mathrm{BC} 3 \mathrm{DH}$ (double haploid) and identified QTL, for shoot water content (SWC) $q S W C-3$, one for shoot dry weight (SDW) $q S D W-3$ and one for leaf bronzing index (LBI) $q L B I-1$ which strongly demonstrated that all of these QTL had significant role in rice response to Fe toxicity tolerance. Liu et al. (2016) identified two QTL using IL (Introgression lines) population derived from japonica (02428) and indica (Minghui63) and reported two QTL, $q R S D W-11, q R R D W-2$ independent of genetic background. A QTL $q S D W-5$ was identified recently which expressed under both experimental conditions with similar additive effects suggesting the genetic overlap between Fe toxicity tolerance and zinc toxicity tolerance in rice (Zhang et al., 2013). Zhang et al. (2017) identified a putative QTL $q S F W-2$ with a positive additive effect which showed that the genes behind this QTL were contributed from the donor parent. These all are reported QTL for Fe toxicity tolerance and more breeding strategies and efficient screening techniques are required for the identification of tolerant genotypes of rice. Some of the putative QTL identified under Fe stress in rice are shown below in Table 2. Figure 3 showed the way of novel phenotypic screening techniques to enhance Fe toxicity tolerance in rice genotypes.

\section{Novel breeding and screening techniques for Fe toxicity tolerance in rice}

Several molecular breeding techniques are used by researchers to improve Fe tolerance in rice. Molecular breeding aims to identify and transfer genes for improving heavy metals tolerance is more reliable technique. Marker assisted selection (MAS) includes using of markers for construction of linkage map to identify the putative genes and to clone the genes for speed up molecular breeding to enhance Fe tolerance in rice. This breeding approach is becoming more and more beneficial which more efficient and time saving approach is as compare to conventional breeding approaches. Use of backcross recombinant inbred lines (BRILs) populations is ideal population for targeted 
gene cloning and to speed up molecular breeding for improving Fe tolerance in rice (Rasheed et al., 2020a). An effective screening technique is required to characterize the resistance of genotypes at seedling stage. Seedling stage is ideal stage to identify the genotypes against different metals stress. One of the best way is to use preliminary screening technique to evaluate the genotypes against different levels of Fe toxicity. Parents and population should be grown in hydroponic condition and expose to different level of stress at seedling stage. In this way most effective dose of stress would be determined and that can be further used to screen the genotypes. Resistant genotypes could be selected for different seedling traits which are indicators of metals tolerance (Rasheed et al., 2020a). Resistant genotypes could be used for QTL mapping which lead to MAS selection. Therefore, this screening technique is needed for effective QTL mapping.

Table 2. Putative QTL identified in rice during exposure to Fe stress

\begin{tabular}{|c|c|c|c|c|c|c|c|}
\hline Parents & Population & Traits & Marker & Chr & QTL & PVE\% & Reference \\
\hline $\begin{array}{l}\text { glaberrim/ } \\
\text { Caiapo }\end{array}$ & $\begin{array}{c}220 \\
\text { BC3DH }\end{array}$ & SWC & $\begin{array}{c}\text { RM-251- } \\
\text { RM238 }\end{array}$ & 3 & $q S W C-3$ & 5.1 & $\begin{array}{l}\text { (Dufey et } \\
\text { al., 2015) }\end{array}$ \\
\hline $\begin{array}{c}\text { glaberrim/ } \\
\text { Caiapo }\end{array}$ & $\begin{array}{c}220 \\
\text { BC3DH }\end{array}$ & SDW & $\begin{array}{c}\text { RM-60- } \\
\text { RM22 }\end{array}$ & 3 & $q S D W-3$ & 5.3 & $\begin{array}{l}\text { (Dufey et } \\
\text { al., 2015) }\end{array}$ \\
\hline $\begin{array}{c}\text { glaberrim/ } \\
\text { Caiapo }\end{array}$ & $\begin{array}{c}220 \\
\text { BC } 3 D H\end{array}$ & LBI & $\begin{array}{l}\text { RM208- } \\
\text { RM266 }\end{array}$ & 1 & $q L B I-1$ & 4.7 & $\begin{array}{l}\text { (Dufey et } \\
\text { al., 2015) }\end{array}$ \\
\hline Azucena/IR64 & 164RIL & $1000 \mathrm{GW}$ & $\begin{array}{l}\text { RM034- } \\
\text { RM246 }\end{array}$ & 1 & $q G W-1$ & & $\begin{array}{l}\text { (Dufey et } \\
\text { al., 2012) }\end{array}$ \\
\hline Azucena/IR64 & 164RIL & $\mathrm{CCI}$ & $\begin{array}{l}\text { RM324- } \\
\text { RM118 }\end{array}$ & 7 & $q C C I-7$ & 33.9 & $\begin{array}{l}\text { (Dufey et } \\
\text { al., 2012) }\end{array}$ \\
\hline Azucena/IR64 & 164RIL & NSP & $\begin{array}{l}\text { RM132- } \\
\text { RM231 }\end{array}$ & 3 & $q N S P-3$ & & $\begin{array}{l}\text { (Dufey et } \\
\text { al., 2010) }\end{array}$ \\
\hline MP & 873RIL & SL & SNP & 1 & $q S L-1$ & 18 & $\begin{array}{l}\text { (Meng et } \\
\text { al., 2017) }\end{array}$ \\
\hline MP & 873RIL & RL & SNP & 8 & $q R L-8$ & & $\begin{array}{l}\text { (Meng et } \\
\text { al., 2017) }\end{array}$ \\
\hline IR29/Pokkali & RIL/CSSL & LBI & 173SNP/83SSR & 1 & $\begin{array}{c}\text { qFETOX-1- } \\
1\end{array}$ & 10.6 & $\begin{array}{c}\text { (Wu et al., } \\
2014)\end{array}$ \\
\hline IR29/Pokkali & RIL/CSSL & LBI & 173SNP/83SSR & 1 & $\begin{array}{c}\text { qFETOX-1- } \\
2\end{array}$ & 12 & $\left(\begin{array}{c}\text { (Wu et al., } \\
2014)\end{array}\right.$ \\
\hline 02428/Minghui63 & IL & RSDW & $384 \mathrm{SNP}$ & 11 & $q F R S D W-11$ & 10.95 & $\begin{array}{c}\text { (Liu et al., } \\
2016)\end{array}$ \\
\hline 02428/Minghui63 & IL & RRDW & 384 SNP & 2 & qFRRDW-2 & 8.68 & $\begin{array}{c}\text { (Liu et al., } \\
2016)\end{array}$ \\
\hline Lemont/Teqing & BIL & SDW & 308SNP & 5 & $q S D W-5$ & & $\begin{array}{l}\text { (Zhang et } \\
\text { al., 2013) }\end{array}$ \\
\hline Indica & $\begin{array}{l}222 \text { Indica- } \\
\text { accessions }\end{array}$ & SFW & $395,553 \mathrm{SNP}$ & 2 & $q S F W-2$ & 10.2 & $\begin{array}{l}\text { (Zhang et } \\
\text { al., 2017) }\end{array}$ \\
\hline
\end{tabular}




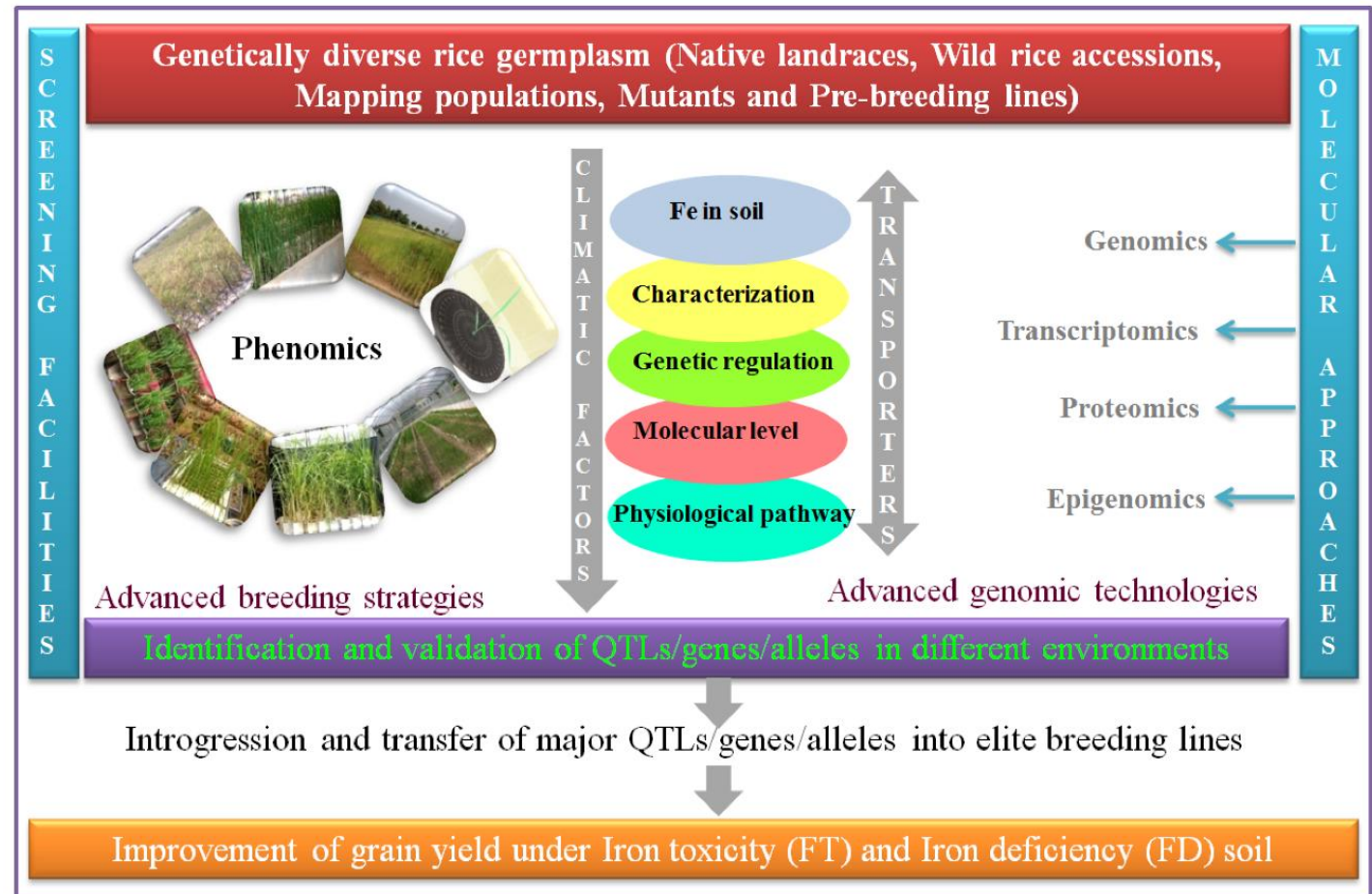

Figure 3. A schematic way of presentation of innumerable phenotypic screening techniques and omics-based approaches to increase iron toxicity tolerance in rice cultivars (Taken from

(Mahender et al., 2019)

\section{Wild relatives as potential source for Fe tolerance in rice}

Wild relative constitutes a valuable gene pool that can be used to breed novel rice genotypes which can be tolerated to abiotic stresses like Fe toxicity. By transferring genes from these wild parents we can efficiently improve Fe toxicity tolerance in rice to sustain rice production. In a study conducted by Bierschenk et al. (2020) screened 75 rice genotypes, including 16 local genotypes, one glaberrima, and 58 wild genotypes which representing 21 species to study Fe toxicity tolerance. Plants were evaluated in green house and were treated with control and Fe stress during vegetative growth stage. Foliar Fe treatment were indicators of Fe toxicity during both stress treatments. Plants with chronic stress reduced yield due to spike fertility. Both wild and local genotypes showed variation in their response to Fe toxicity. Some of the wild relatives performed higher in individual traits towards Fe toxicity. These results showed that Fe toxicity can be improved by domestication of wild parents and to transfer their genes into domestic cultivars.

\section{Conclusion}

Fe toxicity is a polygenetic trait in rice, and there are many genetic and physiological basis of Fe toxicity tolerance. Moreover, many regulators are involved in Fe regulation at various levels. Here we provided a strong theoretical base of rice response to excessive $\mathrm{Fe}$ and genetic basis of Fe regulation in rice, genes and QTLs involving in regulation and tolerance of Fe toxicity. This review concluded that the use of molecular markers, high-resolution population, rice gene pool and wild relatives is a potential 
strategy to improve Fe toxicity tolerance in rice crop. Secondly many identified QTL discussed here are needed to transfer into susceptible lines through QTL pyramiding. Many $\mathrm{Fe}$ transporter is needed to identify to unfold their role in Fe toxicity and its regulation and more efficient breeding techniques are required to screen Fe tolerant rice genotypes.

\section{Future perspectives}

$\mathrm{Fe}$ is an essential element for rice and regulates rice growth when supplied in optimum concentration, but higher concentrations of Fe lead to induction of many deleterious changes in the crop which significantly reduces growth and production. There are certain levels in the cell, where Fe deficiency is regulated by using metabolic pathways. The physiological and biochemical basis of Fe regulation are clearly described in many plants but the molecular basis of Fe toxicity tolerance has not fully characterized. Here we provided a strong theoretical base of rice response to excessive $\mathrm{Fe}$ and genetic basis of $\mathrm{Fe}$ regulation in rice and genes involved in $\mathrm{Fe}$ toxicity tolerance. Many genes described here are associated with previously identified QTL and some of them are regulators that are controlled by VIT, FNP2 like carriers, MIT PIC1, FPN2 like carriers, MIT, PICl transporters, ferritin, OsFRO1, OsIRO3 \& OsbHL133, and OsNRAMP7 \& OsNRAMP8. Many molecules responsible for Fe intra and inter cellular movement are still unidentified, linked to the huge number of unidentified genes in rice. Recently 3000 rice genomes were studied which highlighted the possibilities of validating these unannotated genes and identify their expression. The genome sequence for candidate gene can be accessed, moreover, the use of molecular markers that help in screening the Fe tolerant genotypes from susceptible one would be more helpful to accelerate genes pyramiding. The morphological, physiological and molecular basis of Fe toxicity tolerance would facilitate successful breeding if they are targeted to a large extent. The wild relatives of rice should be focused to screen out new sources of Fe toxicity tolerance and to transfer the novel genes in rice that could be exploited in rice breeding.

Acknowledgements. Authors are thankful to the Prof WU Ziming for his financial support during entire study. Authors are also thankful to the lab fellows for their support during manuscript preparation.

Funding. The research was supported by the National Natural Science Foundation of China (71963020 and 31760350), the National Key Research and Development Program of China (2018YFD0301102), the Jiangxi natural Science foundation (20181BAA208055 and 20202BABL205020), the Key Research and Development Program of Jiangxi Province (20171ACF60018 and 20192ACB60003), the Jiangxi Agriculture Research System (JXARS-18) and Projects of Water Science and Technology of Jiangxi Province (KT201628).

\section{REFERENCES}

[1] Aamer, M., Hassan, M. U., Abid, A., Su, Q., Liu, Y., Rasheed, A., Muhammad, A. U. K., Tahir, A. K., Huang, G. (2018): Foliar application of glycinebetaine (GB) alleviates the cadmium $(\mathrm{Cd})$ toxicity in spinach through reducing $\mathrm{Cd}$ uptake and improving the activity of antioxidant systems. - Applied Ecology and Envronment Research 16(6): 7575-7583.

[2] Aoyama, T., Kobayashi, T., Takahashi, M., Nagasaka, S., Usuda, K., Kakei, Y. (2009): OsYSL18 is a rice iron (III)-deoxymugineic acid transporter specifically expressed in reproductive organs and phloem of lamina joints. - Plant Molecular Biology 70: 681-692. 
[3] Audebert, A., Sahrawat, K. L. (2000): Mechanisms for iron toxicity tolerance in lowland rice. - Journal of Plant Nutrition 23(11-12): 1877-1885.

[4] Audebert, A. (2006): Iron toxicity in rice-environmental conditions and symptoms. - Iron Toxicity in Rice-Based System in West Africa, WARDA, Cotonou 18: 33.

[5] Bashir, K., Ishimaru, Y., Nishizawa, N. K. (2010): Iron uptake and loading into rice grains. - Rice 3: 122-130.

[6] Bashir, K., Ishimaru, Y., Shimo, H., Nagasaka, S., Fujimoto, M., Takanashi, H., Tsutsumi, N., Nakanishi, H., Nishizawa, N. K. (2011): The rice mitochondrial iron transporter is essential for plant growth. - Nature Communications 2: 1-7.

[7] Bashir, K., Hanada, K., Shimizu, M., Seki, M., Nakanishi, H., Nishizawa, N. K. (2014): Transcriptomic analysis of rice in response to iron deficiency and excess. - Rice 7: 1-15.

[8] Besson-Bard, A., Gravot, A., Richaud, P., Auroy, P., Duc, C., Gaymard, F., Taconnat, L., Renou, J. P., Pugin, A., Wendehenne, D. (2009): Nitric oxide contributes to cadmium toxicity in Arabidopsis by promoting cadmium accumulation in roots and by upregulating genes related to iron uptake. - Plant Physiology 149: 130-131.

[9] Bierschenk, B., Tagele, M. T., Ali, B., Ashrafuzzaman, M. D., Wu, L., Becker, M., Frei, M. (2020): Evaluation of rice wild relatives as a source of traits for adaptation to iron toxicity and enhanced grain quality. - Plos One 15(1): 1-17.

[10] Brumbarova, T., Bauer, P., Ivanov, R. (2015): Molecular mechanisms governing Arabidopsis iron uptake. - Trends Plant Science 20: 124-133.

[11] Chandel, G., Banerjee, S., Verulkar, S. (2010): Expression profiling of metal homeostasis related candidate genes in rice (Oryza spp.) using semi quantitative RT-PCR analysis. Rice Genetics Newsletter 25: 44-47.

[12] Darbani, B., Briat, J. F., Holm, P. B., Husted, S., Noeparvar, S., Borg, S. (2013): Dissecting plant iron homeostasis under short and long-term iron fluctuations. Biotechnology Advances 31: 1292-1307.

[13] Das, K., Roychoudhury, A. (2014): Reactive oxygen species (ROS) and response of antioxidants as ROS-scavengers during environmental stress in plants. - Frontiers in Environmental Science 2: 1-13.

[14] Drame, K. N., Saito, K., Kone, B., Chabi, A., Dakouo, D., Annan-Afful, E., Monh, S., Abo, E., Sie, M. (2011): Coping with iron toxicity in the lowlands of subSaharan Africa: experience from Africa Rice Center. - Proceedings of the second Africa Rice Congress, Bamako, Mali. Innovation and partnerships to realize Africa's Rice potential.

[15] Dufey, I., Hakizimana, P., Draye, X. S., Lutts, L., Bertin, P. (2009): QTL mapping for biomass and physiological parameters linked to resistance mechanisms to ferrous iron toxicity in rice. - Euphytica 167: 143-160.

[16] Dufey, I., Hiel, M. P., Hakizimana, P., Draye, X., Lutts, S., Kone, B., Drame, K., Konate, K., Sie, M., Bertin, P. (2012): Multienvironment quantitative trait loci mapping and consistency across environments of resistance mechanisms to ferrous iron toxicity in rice. - Crop Science 52: 539-550.

[17] Dufey, I. X., Draye, S., Lutts, M., Lorieux, C., Martinez Bertin, P. (2015): Novel QTLs in an interspecific backcross Oryza sativa $\times$ Oryza glaberrima for resistance to iron toxicity in rice. - Euphytica 204: 609-625.

[18] Finatto, T., Oliveira, A. C., Chaparro, C., Maia, L. C., Farias, D. R., Woyann, L. G., Mistura, C. C., Soares-Bresolin, A. P., Llauro, C., Panaud, O. (2015): Abiotic stress and genome dynamics: specific genes and transposable elements response to iron excess in rice. - Rice 8: 1-18.

[19] Frei, M., Tetteh, R. N., Razafindrazaka, A. L., Fuh, M. A., Wu, L. B., Becker, M. (2016): Responses of rice to chronic and acute iron toxicity: genotypic differences and biofortification aspects. - Plant and Soil 408: 149-161.

[20] Gallie, D. R. (2012): The role of L-ascorbic acid recycling in responding to environmental stress and in promoting plant growth. - Journal of Experimental Botany 64: 433-443. 
[21] Gross, J., Stein, R. J., Fett-Neto, A. G., Fett, J. P. (2003): Iron homeostasis related genes in rice. - Genetics and Molecular Biology 26: 477-497.

[22] Hell, R., Stephan, U. W. (2003): Iron uptake, trafficking and homeostasis in plants. Planta 216: 541-551.

[23] Hosseini, M., Houshmand, S., Mohamadi, S., Tarang, A., Khodambashi, M., Rahimsoroush, H. (2012): Detection of QTLs with main, epistatic and QTL× environment interaction effects for rice grain appearance quality traits using two populations of backcross inbred lines (BILs). - Field Crops Research 135: 97-106.

[24] Inoue, H., Takahashi, M., Kobayashi, T., Suzuki, M., Nakanishi, H., Mori, S., Nishizawa, A. (2008): Identification and localisation of the rice nicotianamine aminotransferase gene OsNAAT1 expression suggests the site of phytosiderophore synthesis in rice. - Plant Molecular Biology 66: 193-203.

[25] Inoue, H., Kobayashi, T., Nozoye, T., Takahashi, M., Kakei, Y., Suzuki, K., Nakazono, M., Nakanishi, H., Mori, S., Nishizawa, N. K. (2009): Rice OsYSL15 is an iron-regulated iron(III)-deoxymugineic acid transporter expressed in the roots and is essential for iron uptake in early growth of the seedlings. - Journal of Biological Chemistry 284: 34703479 .

[26] Ishimaru, Y., Masuda, H., Bashir, K., Inoue, H., Tsukamoto, T., Takahashi, M. (2010): Rice metal-nicotianamine transporter, OsYSL2, is required for long distance transport of iron and manganese. - Plant Journal 62: 379-390.

[27] Ishimaru, Y., Takahashi, R., Bashir, K., Shimo, H., Senoura, T., Sugimoto, K., Ono, K., Yano, M., Ishikawa, S., Arao, T. (2012): Characterizing the role of rice NRAMP5 in manganese, iron and cadmium transport. - Scientific Reports 2: 1-8.

[28] Jaggard, K. W., Qi, A., Ober, E. S. (2010): Possible changes to arable crop yields by 2050. - Philosophical Transactions of the Royal Society B: Biological Science 365: 28352851.

[29] Jain, A., Connolly, E. L. (2013): Mitochondrial iron transport and homeostasis in plants. - Frontiors in Plant Science 4: 1-7.

[30] Kim, S. A., Guerinot, M. L. (2007): Mining iron: iron uptake and transport in plants. FEBS letters 581: 2273-2280.

[31] Kobayashi, T., Itai, R. N., Nishizawa, N. K. (2014): Iron deficiency responses in rice roots. - Rice 7: 1-11.

[32] Koike, S., Inoue, H., Mizuno, D., Takahashi, M., Nakanishi, H., Mori, S., Nishizawa, N. $\mathrm{K}$. (2004): OsYSL2 is a rice metal-nicotianamine transporter that is regulated by iron and expressed in the phloem. - The Plant Journal 39: 415-424.

[33] Li, G., Kronzucker, H. J., Shi, W. (2016): Root developmental adaptation to Fe toxicity: mechanisms and management. - Plant Signaling Behaviour 11: 1117-1122.

[34] Li, W., Ping, L. (2017): The understanding of the plant iron deficiency responses in Strategy I plants and the role of ethylene in this process by omics approaches. - Frontiers in Plant Science 8: 1-15.

[35] Lin, H., Li, L., Jia, X., Ward, D. M., Kaplan, J. (2011): Genetic and biochemical analysis of high iron toxicity in yeast iron toxicity is due to the accumulation of cytosolic iron and occurs under both aerobic and anaerobic conditions. - Journal of Biological Chemistry 286: 3851-3862.

[36] Liu, H., Soomro, A., Zhu, Y., Qiu, X., Chen, K., Zheng, T., Yang, I., Xing, E. D., Xu, J. (2016): QTL underlying iron and zinc toxicity tolerances at seedling stage revealed by two sets of reciprocal introgression populations of rice (Oryza Sativa L.). - The Crop Journal 4: 280-289.

[37] Mahender, A., Swamy, B., Anandan, A., Ali, J. (2019): Tolerance of iron-deficient and toxic soil conditions in rice. - Plants 8: 1-34.

[38] Matthus, E., Wu, L. B. W., Höller, Y., Becker, S. S., Michael, M. F. (2015): Loci, genes, and mechanisms associated with tolerance to ferrous iron toxicity in rice (Oryza sativa L.). - Theoretical and Applied Genetics 128: 2085-2098. 
[39] Meng, L., Wang, B., Zhao, X., Ponce, K., Qian, Q., Ye, G. (2017): Association mapping of ferrous, zinc, and aluminum tolerance at the seedling stage in indica rice using MAGIC populations. - Frontiers in Plant Science 8: 1-15.

[40] Mengel, K. (1995): Iron availability in plant tissues-iron chlorosis on calcareous soils. In: Abadía, J. (ed.) Iron Nutrition in Soils and Plants. Plant and Soil Sciences 59: 389397.

[41] Mongon, J., Chaiwong, N., Bouain, N., Prom, U., Thai, C., Secco, D., Rouached, H. (2017): Phosphorus and iron deficiencies influences rice shoot growth in an oxygen dependent manner: insight from upland and lowland rice. - International Journal of Molecular Sciences 18: 1-7.

[42] Morrissey, J., Guerinot, M. L. (2009): Iron uptake and transport in plants: the good, the bad, and the ionome. - Chemical Reviews 109: 4553-4567.

[43] Muller, C., Kuki, K. N., Pinheiro, D. T., Souza, L. R., Silva, A. L., Loureiro, M. E., Oliva, M. A., Almeida, A. A. (2015): Differential physiological responses in rice upon exposure to excess distinct iron forms. - Plant and Soil 391: 123-138.

[44] Nakanishi, H., Ogawa, I., Ishimaru, Y., Mori, S., Nishizawa, N. K. (2006): Iron deficiency enhances cadmium uptake and translocation mediated by the $\mathrm{Fe}^{2+}$ transporters OsIRT1 and OsIRT2 in rice. - Soil Science and Plant Nutrition 52: 464-469.

[45] Nozoye, T., Inoue, H., Takahashi, M., Ishimaru, Y., Nakanishi, H., Mori, S. (2007): The expression of iron homeostasis-related genes during rice germination. - Plant Molecular Biology 64: 35-47.

[46] Nugraha, Y., Ardie, S. W., Ghulamahdi, M., Aswidinnoor, H., Suwarno, A. H. (2016): Generation mean analysis of leaf bronzing associated with iron toxicity in rice seedlings using digital imaging methods. - SABRAO Journal of Breeding and Genetics 48: 453464.

[47] Ogo, Y., Kakei, Y., Nakanishi Itai, R., Kobayashi, T., Nakanishi, H., Nishizawa, N. K. (2014): Tissue-specific transcriptional profiling of iron-deficient and cadmium-stressed rice usinglaser capture microdissection. - Plant Signaling Behaviour 9(8): 1-4.

[48] Onaga, G., Egdane, J., Edema, R., Abdelbagi, I. (2013): Morphological and genetic diversity analysis of rice accessions (Oryza sativa L.) differing in iron toxicity tolerance. - Journal of Crop Science and Biotechnology 16: 53-62.

[49] Onaga, G., Drame, K. N., Ismail, A. M. (2016): Understanding the regulation of iron nutrition: can it contribute to improving iron toxicity tolerance in rice. - Functional Plant Biology 43: 709-726.

[50] Onyango, D. A., Entila, F., Dida, M., Ismail, A. M., Drame, K. N. (2019): Mechanistic understanding of iron toxicity tolerance in contrasting rice varieties from Africa: 1. Morpho-physiological and biochemical responses. - Functional Plant Biology 46: 93-105.

[51] Pennock, D., McKenzie, N. (2015): Montanarella L. Status of the World's Soil Resources. - FAO: Rome, Italy.

[52] Pereira, M., Santos, P., Gomes, C., Vasconcelo, M. W. (2014): Cultivar variability of iron uptake mechanisms in rice (Oryza sativa L.). - Plant Physiology and Biochemistry 85: 21-30.

[53] Quinet, M., Vromman, D., Clippe, A., Bertin, P., Lequeux, H., Dufey, I., Lutts, S., Lefèvre, I. (2012): Combined transcriptomic and physiological approaches reveal strong differences between short- and long-term response of rice (Oryza sativa L) to iron toxicity. - Plant Cell and Environment 35: 1837-1859.

[54] Rasheed, A., Fahad, S., Hassan, M. U., Tahir, M. M., Aamer, M., Wu, Z. M. (2020a): A review on aluminum toxicity and quantitative trait loci mapping in rice (Oryza sativa $\mathrm{L}$ ). - Applied Ecology and Environmental Research 18(3): 3951-3961.

[55] Rasheed, A., Fahad, S., Aamer, M., Hassan, M. U., Tahir, M. M., Wu, Z. M. (2020b): Role of genetic factors in regulating cadmium uptake, transport and accumulation mechanisms and quantitative trait loci mapping in rice. a review. - Applied Ecology and Environmental Research 18(3): 4005-4023. 
[56] Rout, G. R., Sahoo, S. (2015): Role of iron in plant growth and metabolism. Agricultural Science Review 3: 1-24.

[57] Saikia, T., Baruah, K. K. (2012): Iron toxicity tolerance in rice (Oryza sativa L) and its association with anti-oxidative enzyme activity. - Journal of Crop Science 3: 90.

[58] Sikirou, M., Saito, K., Achigan-Dako, E. G., Drame, K. N., Ahanchede, A., Venuprasad, R. (2015): Genetic improvement of iron toxicity tolerance in rice-progress, challenges and prospects in West Africa. - Plant Production Science 18: 423-434.

[59] Sperotto, R. A., Boff, T., Duarte, G., Santos, L. S., Grusak, M. A., Fett, J. P. (2010): Identification of putative target genes to manipulate $\mathrm{Fe}$ and $\mathrm{Zn}$ concentrations in rice grains. - Journal of Plant Physiology 167: 1500-1506.

[60] Stein, R. J., Duarte, G. L., Spohr, M. G., Lopes, S. I. G., Fett, J. P. (2009): Distinct physiological responses of two rice cultivars subjected to iron toxicity under field conditions. - Annual Applied Biology 154: 269-277.

[61] Takahashi, R., Ishimaru, Y., Senoura, T., Shimo, H., Ishikawa, S., Arao, T., Nakanishi, H., Nishizawa, N. K. (2011): The OsNRAMP1 iron transporter is involved in $\mathrm{Cd}$ accumulation in rice. - Journal of Experimental Botany 62: 4843-4850.

[62] Tan, L., Zhu, Y., Fan, T., Peng, C., Wang, J., Sun, L., Chen, C. (2019): OsZIP7 functions in xylem loading in roots and inter-vascular transfer in nodes to deliver $\mathrm{Zn} / \mathrm{Cd}$ to grain in rice. - Biochemical and Biophysical Research Communications 512: 112-118.

[63] Van Oort, P. A. J. (2018): Mapping abiotic stresses for rice in Africa: Drought, cold, iron toxicity, salinity and sodicity. - Field Crops Research 219: 55-75.

[64] Vejchasarn, P., Lynch, J. P., Brown, K. M. (2016): Genetic variability in phosphorus responses of rice root phenotypes. - Rice 9: 1-16.

[65] Vivitha, P., Raveendran, M., Vijayalakshmi, D. (2017): Introgression of QTLs controlling spikelet fertility maintains membrane integrity and grain yield in improved white Ponni derived progenies exposed to heat stress. - Rice Science 24: 32-40.

[66] Wainaina, C. M., Makihara, D., Nakamura, M., Ikeda, A., Suzuki, T., Mizukami, Y., Nonoyama, T., Doi, K., Kikuta, M., Samejima, H. (2018): Identification and validation of QTLs for cold tolerance at the booting stage and other agronomic traits in a rice cross of a Japanese tolerant variety, Hananomai, and a NERICA parent, WAB56-104. - Plant Production Science 21: 132-143.

[67] Wan, J. L., Zhai, H. Q., Wan, J. M., Yasui, H., Yoshimura, A. (2003): Mapping QTL for traits associated with resistance to ferrous iron toxicity in rice (Oryza sativa L.), using japonica chromosome segment substitution lines. - Yi Chuan Xue Bao, Acta Genetica Sinica 30(10): 893-898.

[68] Wang, L., Ying, Y., Narsai, R., Ye, L., Zheng, J., Tian, J., Whelan, K., Shou, H. (2012): Identification of OsbHLH133 as a regulator of iron distribution between roots and shoots in Oryza sativa. - Plant Cell and Environment 36: 224-236.

[69] White, P., Brown, P. (2010): Plant nutrition for sustainable development and global health. - Annals of Botany 105: 1073-1080.

[70] Wu, L. B., Shhadi, M. Y., Gregorio, G., Matthus, E., Becke, M., Frei, M. (2014): Genetic and physiological analysis of tolerance to acute iron toxicity in rice. - Rice 7(1): 8 .

[71] Wu, L. B., Holtkamp, B. F., Wairich, A., Frei, M. (2019): Potassium ion channel gene OsAKT1 affects iron translocation in rice plants exposed to iron toxicity. - Frontiers in Plant Science 10: 579.

[72] Zhang, J., Soomro, A. A., Chai, L., Cui, Y., Wang, X., Zheng, T., Xu, J., Li, Z. (2013): Mapping of QTL for iron and zinc toxicity tolerance at seedling stage using a set of reciprocal introgression lines of rice. - Acta Agronomica Sinica 39: 1754-1765.

[73] Zhang, J., Chen, K., Pang, Y., Naveed, S. A., Zhao, X., Wang, X., Wang, Y., Dingkuhn, M., Pasuquin, J., Li, Z. (2017): QTL mapping and candidate gene analysis of ferrous iron and zinc toxicity tolerance at seedling stage in rice by genome-wide association study. BMC Genomics 18: 1-15. 
[74] Zhao, C., Zhou, L., Ding, D., Zhang, Y., Zhao, Q., Yu, X., Zhu, Z., Chen, T., Yao, S., Wang, C. (2013): Mapping of quantitative trait loci associated with ferrous iron toxicity tolerance at seedling stage based on chromosome segment substitution line in rice. Jiangsu Journal of Agricultural Science 29: 461-467. 